\title{
DFT and $a b$ initio calculations of ionization potentials, proton affinities and bond dissociation enthalpies of aromatic compounds
}

\author{
Denisa Cagardováa, Martin Michalika , Erik Kleina, \\ Vladimír Lukeša ${ }^{\mathrm{a}}$ Zoran Marković ${ }^{\mathrm{b}}$ \\ ${ }^{a}$ Institute of Physical Chemistry and Chemical Physics, Slovak University of Technology in Bratislava, \\ Radlinského 9, SK-812 37 Bratislava, Slovakia \\ ${ }^{b}$ State University of Novi Pazar, Vuka Karadžića bb, 36300 Novi Pazar, Serbia \\ denisa.cagardova@stuba.sk
}

\begin{abstract}
Theoretical study of phenol, thiophenol, benzeneselenol, aniline and their para-amino and paranitro derivatives is presented. Neutral molecules, their deprotonated forms, neutral radicals, and radical cations were studied using three Density Functional Theory (DFT) functionals as well as combined DFT and ab initio $\mathrm{G} 4$ method in order to calculate the $\mathrm{N}-\mathrm{H}, \mathrm{O}-\mathrm{H}, \mathrm{S}-\mathrm{H}$, and $\mathrm{Se}-\mathrm{H}$ bond dissociation enthalpies (BDE), proton affinities of corresponding anions (PA) and ionization potentials (IP) of studied compounds. These quantities represent fundamental reaction enthalpies related to the radical scavenging action of primary antioxidants. Calculated values were compared with available experimental data to assess applicability of the computational approaches employed. M06-2X/6-311++G(d,p) and G4 methods showed the best agreement with the available experimental gas-phase reaction enthalpies.
\end{abstract}

Keywords: Antioxidant; radical; anion; electron-donating group; electron-withdrawing group

\section{Introduction}

Primary antioxidants represent chemical compounds able to scavenge reactive radical intermediates formed during the oxidative reactions in biological systems, food products, synthetic polymers, and other industrial products. In these processes, hydroxyl ( $\left.\mathrm{HO}^{*}\right)$, alkoxyl $\left(\mathrm{RO}^{*}\right)$ and peroxyl (ROO*) radicals play an important role (Rice-Evans et al., 1996). The primary antioxidants comprise essentially (poly)phenolic compounds and secondary aromatic amines (Wolf and Kaul, 1992). They act usually both through chain transfer and through chain termination (Gugumus, 1990).

Hydrogen atom transfer from the antioxidant molecule is often the first step of radical scavenging by primary antioxidants (Gugumus, 1990). From the thermodynamic point of view, the dissociation of $\mathrm{O}-\mathrm{H}$ bond in phenols and $\mathrm{N}-\mathrm{H}$ bond in aromatic amines is described by the bond dissociation enthalpy (BDE)

$$
\mathrm{BDE}=H\left(\mathrm{R}^{\bullet}\right)+H\left(\mathrm{H}^{\bullet}\right)-H(\mathrm{R}-\mathrm{H})
$$

where $H\left(\mathrm{R}^{*}\right)$ is total enthalpy of the formed radical, $H\left(\mathrm{H}^{\circ}\right)$ is total enthalpy of the abstracted hydrogen atom, and $H(\mathrm{R}-\mathrm{H})$ stands for total enthalpy of the molecule. Based on the statistical thermodynamics, total enthalpy $(H)$ at temperature $(T)$ is estimated from the expression

$$
H=E_{0}+\mathrm{ZPE}+\Delta H_{\text {trans }}+\Delta H_{\text {rot }}+\Delta H_{\text {vib }}+R T
$$

where $E_{0}$ is total electronic energy, ZPE denotes the zero-point energy, and $\Delta H_{\text {trans }}, \Delta H_{\text {rot }}$ and $\Delta H_{\text {vib }}$ are translational, rotational and vibrational contributions to enthalpy, respectively. The last term in Eq. 2 represents PV-work converting energy to enthalpy (Atkins, 1998). Proton affinity (PA) of formed anion represents the reaction enthalpy of molecule deprotonation, i.e. of the heterolytic cleavage of the corresponding bond

$$
\mathrm{PA}=H\left(\mathrm{R}^{-}\right)+H\left(\mathrm{H}^{+}\right)-H(\mathrm{R}-\mathrm{H})
$$

where $H\left(\mathrm{R}^{-}\right)$is enthalpy of anion and $H\left(\mathrm{H}^{+}\right)$is total enthalpy of proton. Another important quantity related to the antioxidant action is the adiabatic ionization potential, IP

$$
\mathrm{IP}=H\left(\mathrm{R}-\mathrm{H}^{\bullet+}\right)+H\left(\mathrm{e}^{-}\right)-H(\mathrm{R}-\mathrm{H})
$$

where $H\left(\mathrm{R}-\mathrm{H}^{*+}\right)$ is total enthalpy of the radical cation, and $H\left(\mathrm{e}^{-}\right)$is enthalpy of an electron, $3.145 \mathrm{~kJ} \mathrm{~mol}^{-1}$ (Bartmess, 1994). Proton affinity and ionization potential are reaction enthalpies of the first steps in the Sequential Proton-Loss - Electron Transfer (SPLET) and Single-Electron Transfer Proton Transfer (SET-PT) mechanisms, respectively (Filipović, 2020; Galano and Raúl Alvarez-Idaboy, 2019; Leopoldini et al., 2011).

Experimentally determined BDE, PA and IP values can be obtained using several techniques (Bordwell and Cheng, 1991; Dos Santos and Simoes, 1998; Fujio et al., 1981; Jonsson et al., 1994; Kim et al., 2000; McMahon and Kebarle, 1977; Mulder et al., 
2005): electrochemistry, photoacoustic calorimetry, mass spectrometry, photoelectron spectroscopy, etc. BDE measurements are often carried out in solution-phase (e.g. in water, DMSO, benzene, etc.) and gas-phase values are subsequently estimated based on certain assumptions. Therefore, published experimental BDEs may vary in a wide range. For example, published experimental works suggested the gas-phase $\mathrm{O}-\mathrm{H}$ BDE of phenol to be in the range from $348.5 \mathrm{~kJ} \mathrm{~mol}^{-1}$ to $375.0 \mathrm{~kJ} \mathrm{~mol}^{-1}$ (Dos Santos and Simoes, 1998). In this review, the authors recommend the value of $371.3 \pm 2.3 \mathrm{~kJ} \mathrm{~mol}^{-1}$ for the gas-phase $\mathrm{O}-\mathrm{H}$ BDE of phenol. Using the mass-analyzed threshold ionization technique and literature data, Kim et al. (2000) experimentally determined $\mathrm{O}-\mathrm{H}$ BDE to be $381 \mathrm{~kJ} \mathrm{~mol}^{-1}$. Later, Angel and Ervin (2004) used mass spectrometry (threshold collision-induced dissociation method) determining the value of $359 \pm 8 \mathrm{~kJ} \mathrm{~mol}^{-1}$. Mulder et al. (2005) recommended the experimental gasphase value of $362 \pm 3 \mathrm{~kJ} \mathrm{~mol}^{-1}$ using two gas-phase and three solution-phase values.

Accurate estimation of thermochemistry data from quantum chemical calculations is also a challenging task since the employment of high levels of calculations is necessary to consider the effect of both dynamical and non-dynamical parts of the electron correlation. Thirty years ago, semiempirical methods were intensively used due to the very restricted computational resources. Dewar's MNDO (Dewar and Thiel, 1977) and AM1 (Dewar et al., 1985) methods have been widely employed for enthalpies of formation as well as reaction enthalpies of organic compounds calculations. The latest reparametrized MNDO method, called PM7 method (Stewart, 2013), represents a computationally simple and fast tool for basic thermodynamic characterization of organic compounds. Currently, density functional theory (DFT) calculations are most frequently used due to the lower computational costs in comparison to the ab initio methods. Sensitivity of the results to suitable functional and basis set selection represents a disadvantage of the DFT calculations. An alternative, and generally more accurate, computational approach for the thermochemistry data is based on the Gaussian- $n$ $(\mathrm{G} n)$ theories, which employ a set of calculations of different levels of accuracy and various basis sets to obtain exact energetics (Curtiss et al., 2007). In the G1, G2 and G3 approaches, high level correlation calculations, e.g. QCISD(T) and CCSD(T), with moderate size basis set are combined with energies from lower level calculations, e.g. MP4 and MP2, with larger basis sets to approximate the energies of more expensive calculations (Curtiss et al., 1991 and 1998). In addition, several molecule-independent empirical parameters, higher level correction terms, are included to estimate the remaining deficiencies assuming that they are systematic (Curtiss et al., 2007). The use of geometries and zero-point energies from the density functional theory, application of CCSD(T) energies, inclusion of the $a b$ initio Hartree-Fock limit energy and the addition of higher-level correction parameters in the G4 method (Curtiss and Redfern, 2007) contribute to the largest improvement over the original $\mathrm{G} n$ theories. The G4 theory is a useful tool which may provide benchmark quality results (Curtiss et al., 2007).

Basis sets used in the field of theoretical investigation of thermochemistry and reaction kinetics have to reliably describe all relevant species, i.e. molecules, radicals, deprotonated species and radical cations resulting from electron abstraction. Moreover, the basis set should provide reliable description of intramolecular hydrogen bonds that are very frequent mainly in various (poly)phenolic compounds. Pople's basis sets are somewhat outdated as correlation-consistent or polarization-consistent basis sets typically yield better results with similar resources. Some Pople's basis sets show deficiencies that can lead to incorrect results (Moran et al., 2006). For balanced description of investigated species it is necessary to include both diffusion and polarization functions. Among widely used basis sets count also those developed by Dunning and coworkers (Dunning, 1989) for converging Post-Hartree-Fock calculations enabling extrapolation of results to complete basis sets. The added diffuse functions improve the description of anions and long-range interactions such as van der Waals forces and electric field properties. Because of the rigorous construction of these basis sets, extrapolation can be done for almost any energetic property at the ab initio level of theory. The Sapporo basis sets are compact segmented basis sets designed to efficiently recover the correlation energy of a system. These basis sets were based on the original NOSeC- $n$ ZP sets ( $n=\mathrm{D}, \mathrm{T}, \mathrm{Q})$ (Noro et al., 1997) designed to represent the space spanned by atomic natural orbitals as determined by configuration interaction calculations. The $n \mathrm{ZP}$ sets are based on the primitive sets of Huzinaga and Klobukowski (1993) which were extended by adding higher angular momentum functions for the determination of a set of accurate natural orbitals (Weber et al., 2015). The def2-TZVP basis sets are very appealing because they provide consistent accuracy across the whole periodic table and they are available for all elements up to radon $(Z=86)$ (Weigend and Ahlrichs, 2005), contrary to more commonly used basis sets from the Pople and Dunning groups. These 
Karlsruhe basis sets are very appealing because they constitute balanced and economical basis sets of graded quality from partially polarized double zeta to heavily polarized quadruple zeta for all elements up to radon $(Z=86)$. The extension consists of adding a minimal set of diffuse functions to a subset of elements. The minimally augmented (ma) basis set triple zeta is recommended for general-purpose applications of the density functional theory (Zheng et al., 2011).

In this contribution, comparative G4 and DFT investigation of gas-phase BDEs, PAs and IPs of phenol, thiophenol, benzeneselenol and aniline and their two para-substituted derivatives (Fig. 1) was performed. The $\mathrm{NH}_{2}$ substituent is a strong electron-donating group while the $\mathrm{NO}_{2}$ group is a strong electron-withdrawing group. Para-substituted compounds represent a suitable set of model compounds, where the steric effects of a substituent do not influence the studied group homolytic and heterocyclic dissociations. DFT data were calculated using the most frequently employed functionals, i.e. B3LYP, M06-2X, and PBE0, in combination with various basis sets. B3LYP hybrid functional represents the most popular functional for BDE, IP, and PA calculations. The newer M06-2X functional was optimized for the calculations of thermochemistry and kinetics and it should overcome the known imperfections of B3LYP. PBE0 functional belongs to the generalized gradient approximation functionals and is quite popular as it usually provides reliable results. The obtained theoretical results were compared also with calculated semiempirical PM7 data and available experimental values.

The Pople's basis set $6-311++\mathrm{G}(\mathrm{d}, \mathrm{p})$ provides reliable molecular geometries and reaction enthalpies for phenols and anilines (Poliak and Vagánek, 2013; Klein and Lukeš, 2006; Škorňa et al., 2016) and it is still widely employed in antioxidant action thermochemistry calculations. The remaining basis sets employed have comparable size but different origins.

\section{Computational details}

Quantum chemical calculations were performed using the Gaussian 16 program package (Frisch et al., 2016). M06-2X (Zhao and Truhlar, 2008), B3LYP (Becke's three parameter Lee-Yang-Parr) (Lee et al., 1988; Becke, 1988) and PBE0 (Adamo and Barone, 1999) functionals were employed. The energy cut-off was $10^{-5} \mathrm{~kJ} \mathrm{~mol}^{-1}$ and the final RMS energy gradient was below $0.01 \mathrm{~kJ} \mathrm{~mol}^{-1} \mathrm{~A}^{-1}$. For all calculations, 6-311++G(d,p) (Hariharan and Pople, 1973; Rassolov et al., 1998), aug-cc-pVTZ (Kendall et al., 1992; Woon and Dunning, 1993), ma-def2TZVP (Weigend and Ahlrichs, 2005) and Sapporo
(Noro et al., 1997) basis sets were used. Frequency analysis confirmed that the found species are in real energy minima (no imaginary frequencies). All thermodynamic quantities were evaluated for the temperature of $298.15 \mathrm{~K}$. The total gas-phase enthalpies of the hydrogen atom are $-1301.81 \mathrm{~kJ} \mathrm{~mol}^{-1}$ for M06-2X, -1324.87 kJ mol ${ }^{-1}$ for B3LYP, and $-1324.87 \mathrm{~kJ} \mathrm{~mol}^{-1}$ for the PBE0 functional. In case of the PM7 method, formation enthalpy of the hydrogen atom is $-1324.87 \mathrm{~kJ} \mathrm{~mol}^{-1}$ and proton formation enthalpy is $1536.2 \mathrm{~kJ} \mathrm{~mol}^{-1}$ (Atkins, 1998). The G4 enthalpy of hydrogen atom is $-1310.3 \mathrm{~kJ} \mathrm{~mol}^{-1}$. Gas-phase proton and electron total enthalpies are $6.197 \mathrm{~kJ} \mathrm{~mol}^{-1}$ and $3.145 \mathrm{~kJ} \mathrm{~mol}^{-1}$, respectively. In case of M06-2X calculations, the starting geometries were taken from optimized B3LYP method because of convergence problems with the starting geometries pre-optimized by molecular mechanics.

\section{Results and Discussion}

The first part of discussion is focused on the description of optimal geometries of the studied molecules with planar aromatic ring. As it is shown in Fig. 1, $\varphi\left(\varphi^{\prime}\right)$ represent dihedral angles between hydrogen atom(s) of the functional group, heteroatom and two carbon atoms of the benzene ring. The parent phenol and thiophenol molecules exhibit planar gas-phase geometries due to the planar arrangement of $-\mathrm{OH}$ and $-\mathrm{SH}$ groups (see Tab. 1). In case of benzeneselenol, $-\mathrm{SeH}$ group is twisted only for B3LYP/6-311++G(d,p) with the dihedral angle of $35^{\circ}$. Hydrogen atoms of the $-\mathrm{NH}_{2}$ group in aniline are uniformly tilted from the ring plane and its plane of symmetry is perpendicular to the molecular aromatic plane (see Fig. 2a). DFT methods predict the values of dihedral angles, $\varphi$ and $\varphi^{\prime}$, to be between $\pm 24^{\circ}$ to $\pm 27^{\circ}$. PM7 geometry of aniline is more planar, i.e. $\varphi$ and $\varphi^{\prime}$ reach $\pm 17^{\circ}$. The electron donating amino group leads to perpendicular arrangement of $-\mathrm{SH}$ and - SeH groups (see Fig. 2a). On the other hand, the hydroxyl group of substituted phenol is planar and the absolute values of selected dihedral angles for both amino groups in para-aminoaniline are slightly higher, by about $3^{\circ}$, in comparison to those for aniline (Tab. 2). In general, radical formation after homolytic $\mathrm{O}-\mathrm{H}, \mathrm{S}-\mathrm{H}, \mathrm{Se}-\mathrm{H}$ and $\mathrm{N}-\mathrm{H}$ bond cleavage mostly decreases the absolute values of the dihedral angle. Small changes in planarity were observed for para-aminobenzeneselenol. The presence of a nitro group in the para position is responsible for molecules' planarity (Tab. 3). In case of para-nitroaniline, DFT values of dihedral angles $\varphi$ and $\varphi^{\prime}$ lie between $\pm 17^{\circ}$ to $\pm 21^{\circ}$. Semiempirical PM7 geometries are planar. 
Electron abstraction from parent molecules and para-amino derivatives (Tab. 4) planarizes molecular geometry. Significant changes in the structure were observed for anions formed from para-aminophenol and aniline when compared to parent molecules. The aromatic ring plane represents the mirror plane of the amino group (see Fig. 2b). For para-aminothiophenol and para-aminobenzeneselenol, DFT dihedral angle $\varphi$ and $\varphi^{\prime}$ values are in the range from $\pm 30^{\circ}$ to $\pm 31^{\circ}$. Here, the mirror plane of the amino group is perpendicularly oriented towards the ring plane. Identical situation was found for electroneutral para-amino derivatives (e.g. Fig. 2a).

$\mathrm{NO}_{2}$ group in the radical cation of para-nitrophenol is slightly rotated with respect to the aromatic ring (see Fig. 2c). The maximal dihedral angles, $\Theta=\Theta^{\prime}$, were found for B3LYP and PBE0 functionals (from $41^{\circ}$ to $46^{\circ}$, see Tab. 5), while M06-2X dihedral angles are lower by approximately one half. In case of the remaining nitro derivatives, M06-2X optimal geometries are mostly planar. The anionic forms are planar for PM7 method as well as for all tested DFT functionals.

Tab. 6 summarizes the computed gas-phase $\mathrm{O}-\mathrm{H}, \mathrm{S}-\mathrm{H}, \mathrm{Se}-\mathrm{H}$ and $\mathrm{N}-\mathrm{H}$ bond dissociation enthalpies. For example, found BDE values of phenol are in the range from $347 \mathrm{~kJ} \mathrm{~mol}^{-1}$ to $352 \mathrm{~kJ} \mathrm{~mol}^{-1}$ for B3LYP, from $370 \mathrm{~kJ} \mathrm{~mol}^{-1}$ to $375 \mathrm{~kJ} \mathrm{~mol}^{-1}$ for M06-2X and from $347 \mathrm{~kJ} \mathrm{~mol}^{-1}$ to $350 \mathrm{~kJ} \mathrm{~mol}^{-1}$ for PBE0. Among all DFT results, M06-2X/6-311++G(d,p) value of $370 \mathrm{~kJ} \mathrm{~mol}^{-1}$ is in best accordance with the last recommended gasphase value of $362.8 \pm 2.9 \mathrm{~kJ} \mathrm{~mol}^{-1}$ (Mulder et al., 2005). $\mathrm{G} 4 \mathrm{BDE}=367 \mathrm{~kJ} \mathrm{~mol}^{-1}$ is closest to the recommended value while $\mathrm{PM} 7 \mathrm{BDE}=313 \mathrm{~kJ} \mathrm{~mol}^{-1}$ is significantly underestimated. Similar trends were obtained also for the remaining non-substituted molecules. However, for aniline, M06-2X/6$311++\mathrm{G}(\mathrm{d}, \mathrm{p}) \mathrm{N}-\mathrm{H}$ BDE is closer to experimental data than the G4 one. Nevertheless, the minimal effect of a basis set for individual DFT functionals was found for the largest benzeneselenol molecule (Tab. 6a).

Compared to non-substituted molecules, electrondonating substituents decrease the studied BDEs, whereas electron-withdrawing groups induce an increase in BDE (Tab. 6b, c). In case of nitroderivatives of thiophenol and benzeneselenol, the DFT functionals predicted negligible substituent effect for all basis sets. Maximum differences in BDE, compared with non-substituted molecules, were $1 \mathrm{~kJ} \mathrm{~mol}^{-1}$. The reference $\mathrm{G} 4$ method gave larger energy differences (up to $6 \mathrm{~kJ} \mathrm{~mol}^{-1}$ ).

Electron abstraction from an electroneutral molecule is an endothermic process and the found adiabatic ionization potentials are compiled in
Tab. 7. These represent typical values for organic molecules with one aromatic ring. Comparing the few available experimental data, B3LYP and PBE0 functionals tend to underestimate IPs. On the other hand, the M06-2X functional gave reasonable results for all used basis sets. Like BDEs, electron-donating groups induce a drop in IP and electron-withdrawing groups induce a rise in IP.

Gas-phase proton affinities (Eq. 3) are substantially higher than BDEs, i.e. heterolytic cleavage of $\mathrm{O}-\mathrm{H}$, $\mathrm{S}-\mathrm{H}, \mathrm{Se}-\mathrm{H}$ and $\mathrm{N}-\mathrm{H}$ bonds in the gas-phase is not energetically favored. Available experimental data were obtained from various mass spectrometry experiments; however, they (Tab. 8) are very scarce. Within the group of non-substituted studied molecules containing chalcogenes, proton affinities are decreasing from phenol to benzeneselenol. In case of aniline, PA is the highest one (e.g. for B3LYP/6$311++\mathrm{G}(\mathrm{d}, \mathrm{p}), \mathrm{PA}($ aniline $\left.)=1534 \mathrm{~kJ} \mathrm{~mol}^{-1}\right)$. For all computational approaches, PA of aniline is roughly by $80 \mathrm{~kJ} \mathrm{~mol}^{-1}$ higher than that of phenol. Results in Tab. 8 also show that the PM7 method underestimates PAs which is surprising because PM3 method gives PAs of thiophenols in very good agreement with those of the B3LYP/6-311++G(d,p) method (Pankratov and Shalabai, 2004; Rimarčík et al., 2011).

Electron-donating $\mathrm{NH}_{2}$ group located in the para position causes a slight increase in PA, whereas electron-withdrawing $\mathrm{NO}_{2}$ group is responsible for significant drop in PA. DFT methods show ca $100 \mathrm{~kJ} \mathrm{~mol}^{-1}$ decrease in case of phenols and anilines. In thiophenols and benzeneselenols, drop in $\mathrm{PA}$ reaches ca $80 \mathrm{~kJ} \mathrm{~mol}^{-1}$. The $\mathrm{G} 4$ method predicts lower differences between non-substituted molecules and para-nitro derivatives.

\section{Conclusions}

In this article, theoretical study of phenol, thiophenol, benzeneselenol, aniline and their para-nitro and para-amino derivatives is presented. Structures of the investigated molecules, corresponding radical cations, anions and radicals were studied using DFT functionals, $a b$ initio G4 and semiempirical PM7 quantum chemical methods. The obtained total enthalpies enabled calculations of $\mathrm{N}-\mathrm{H}, \mathrm{O}-\mathrm{H}$, $\mathrm{S}-\mathrm{H}$ and $\mathrm{Se}-\mathrm{H}$ bond dissociation enthalpies, proton affinities, and ionization potentials which belong to the most important thermodynamic characteristics of antioxidants. Calculated quantities were compared with available experimental values to ascertain the suitability of the used approaches. The best agreement with the experimental values was obtained for M06-2X/6-311++G(d,p) and $a b$ initio G4 methods. For phenols, excellent mutual 
agreement between M06-2X/6-311++G(d,p) and B3LYP/6-311++G(d,p) proton affinities was also found. Semiempirical PM7 method, providing most planar structures of the studied species, tends to underestimate the investigated quantities with exception of ionization potentials, which are overestimated.

\section{Acknowledgment}

This work was supported by the Slovak Research and Development Agency under the contract no. SKSRB-18-0016. We are grateful to the HPC center at the Slovak University of Technology in Bratislava, which is a part of the Slovak Infrastructure of High Performance Computing (SIVVP project, ITMS code 26230120002, funded by the European region development funds, $E R D F)$ for the computational time and resources made available. V.L. and E.K. thank the Ministry of Education, Science, Research and Sport of the Slovak Republic for funding within the scheme "Excellent research teams". D.C. would like to thank for support from the STU Grant scheme for Support of Young Researchers (1619).

\section{References}

Adamo C, Barone V (1999) J. Chem. Phys. 110: 6158-6169. Angel LA, Ervin KM (2004) J. Phys. Chem. A 108: 8346-8352.

Atkins PW (1998) Physical Chemistry, 6th ed., Oxford University Press, Oxford.

Bartmess JE (1994) J. Phys. Chem. 98: 6420-6424.

Bartmess JE, Scott JA, McIver RT Jr (1979) J. Am. Chem. Soc. 101: 6046-6056.

Becke AD (1988) Phys. Rev. A 38: 3098-3100.

Bordwell FG, Cheng J-P (1991) J. Am. Chem. Soc. 113: 1736-1743.

Bordwell FG, Zhang X-M, Cheng J-P (1993) J. Org. Chem. 58: 6410-6414.

Bordwell FG, Zhang X-M, Satish AV, Cheng J-P (1994) J. Am. Chem. Soc. 116: 6605-6610.

Curtiss LA, Raghavachari K, Redfern PC, Rassolov V, Pople JA (1998) J. Chem. Phys. 109: 7764-7776.

Curtiss LA, Raghavachari K, Trucks GW, Pople JA (1991) J. Chem. Phys. 94: 7221-7230.

Curtiss LA, Redfern PC, Raghavachari K (2007) J. Chem. Phys. 126: 084108.

Denisov ET (1995) Polym. Degrad. Stab. 49: 71-75.

Dewar MJS, Thiel W (1977) J. Am. Chem. Soc. 99: 4899-4907.

Dewar MJS, Zoebisch EG, Healy EF, Stewart JJP (1985) J. Am. Chem. Soc. 107: 3902-3909.

Dos Santos RMB, Muralha VSF, Correia CF, Guedes RC, Cabral BJC, Simoes JAM (2002) J. Phys. Chem. A 106: 9883-9889.

Dos Santos RMB, Simoes JAM (1998) J. Phys. Chem. Ref. Data 27: 707-739.

Dunning TH (1989) J. Chem. Phys. 90: 1007-1023.

Faulk JD, Dunbar RC, Lifshitz C (1990) J. Am. Chem. Soc. 112: 7893-7899.

Filipović, N. (2020) Computational Modeling in Bio- engineering and Bioinformatics, Academic Press, pp. 211-256. ISBN 978-0-12-819583-3.

Frisch MJ, Trucks GW, Schlegel HB, Scuseria GE, Robb MA, Cheeseman JR, Scalmani G, Barone V, Petersson GA, Nakatsuji H, Li X, Caricato M, Marenich AV, Bloino J, Janesko BG, Gomperts R, Mennucci B, Hratchian HP, Ortiz JV, Izmaylov AF, Sonnenberg JL, Williams-Young D, Ding F, Lipparini F, Egidi F, Goings J, Peng B, Petrone A, Henderson T, Ranasinghe D, Zakrzewski VG, Gao J, Rega N, Zheng G, Liang W, Hada M, Ehara M, Toyota K, Fukuda R, Hasegawa J, Ishida M, Nakajima T, Honda Y, Kitao O, Nakai H, Vreven T, Throssell K, Montgomery JA Jr., Peralta JE, Ogliaro F, Bearpark MJ, Heyd JJ, Brothers EN, Kudin KN, Staroverov VN, Keith TA, Kobayashi R, Normand J, Raghavachari K, Rendell AP, Burant JC, Iyengar SS, Tomasi J, Cossi M, Millam JM, Klene M, Adamo C, Cammi R, Ochterski JW, Martin RL, Morokuma K, Farkas O, Foresman JB, Fox DJ (2016) Gaussian 16, Revision B.01, Gaussian, Inc., Wallingford CT.

Fujio M, McIver RT, Taft RW (1981) J. Am. Chem. Soc. 103: 4017-4029

Galano A, Raúl Alvarez-Idaboy J (2019) Int. J. Quant. Chem. 119: e25665.

Gugumus F (1990) Oxidation inhibition in organic materials, 1, CRC Press, Boca Raton.

Hariharan PC, Pople JA (1973) Theor. Chim. Acta 28: 213-222.

Huzinaga S, Klobukowski M (1993) Chem. Phys. Lett. 212: 260 .

Jonsson M, Lind J, Eriksen TE, Merenyi G (1994) J. Am. Chem. Soc. 116: 1423-1427.

Kendall RA., Dunning Jr. TH, Harrison RJ (1992) J. Chem. Phys. 96: 6796-806.

Kim HT, Green RJ, Qian J, Anderson SL (2000) J. Chem. Phys. 112: 5717-5721.

Klein E, Lukeš V (2006) Chem. Phys. 330: 515-525.

Kobayashi T, Nagakura S (1975) J. Electron. Spectrosc. Relat. Phenom. 6: 421-427.

Lee C, Yang W, Parr RG (1988) Phys. Rev. B 37: 785-789.

Leeck DT, Li R, Chyall LJ, Kenttämaa HI (1996) J. Phys. Chem. 100: 6608-6611.

Leopoldini M, Russo N, Toscano M (2011) Food Chemistry 125: 288-306.

Lind J, Shen X, Eriksen TE, Merenyi G (1990) J. Am. Chem. Soc. 112: 479-482.

Lipert RJ, Colson SD (1990) J. Chem. Phys. 92: 3240-3241.

Luo YR (2007) Comprehensive Handbook of Chemical Bond Energies, CRC Press, Boca Raton, New York.

Mandado M, Graña AM, Mosquera RA (2004) Chem. Phys. Lett. 400: 169-174.

McMahon TB, Kebarle P (1977) J. Am. Chem. Soc. 99: 2222-2230.

Moran D, Simmonett AC, Leach, FE III, Allen WD, Schleyer, PvR, Schaefer, HF (2006) J. Am. Chem. Soc. 128: 9342-9343.

Mulder P, Korth HG, Pratt DA, DiLabio GA, Valgimigli L, Pedulli GF, Ingold KU (2005) J. Phys. Chem. A 109: 2647-2655.

Newcomb M, Manek MB, Glenn AG (1991) J. Am. Chem. Soc. 113: 949-958.

Noro T, Sekiya M, Koga T (1997) Theor. Chem. Acc. 98: 25-32.

Poliak P, Vagánek A (2013) Acta Chimica Slovaca 6: 64-72. 
Potapov VK, Kardash IE, Sorokin VV, Sokolov SA, Evlasheva TI (1972) Khim. Vys. Energ. 6: 392.

Pankratov AN, Shalabai AV (2004). J. Struct. Chem. 45: 756-761.

Rassolov V, Pople JA, Ratner M, Windus TL (1998) J. Chem. Phys. 109: 1223-1229.

Rice-Evans CA, Miller NJ, Paganga G (1996) Free Radical Biology and Medicine 20: 933-956.

Rimarčík J, Lukeš V, Klein E, Rottmannová L (2011) Comp. Theor. Chem. 967: 273-283.

Stewart JJP (2013) J. Mol. Model. 19: 1-32.

Škorňa P, Rimarčík J, Poliak P, Lukeš V, Klein E (2016) Comput. Theor. Chem. 1077: 32-38.

Taft R, Bordwell FG (1988) Acc. Chem. Res. 21: 463-469.

Takahashi M, Ozeki H, Kimura K (1992) J. Chem. Phys. 96: 6399-6406.

Venimadhavan S, Amarnath K, Harvey NG, Cheng J-P, Arnett GM (1992) J. Am. Chem. Soc. 114: 221-229.

Wayner DDM, Lusztyk E, Pagé D, Ingold KU, Mulder P, Laarhoven LJJ, Aldrich HS (1995) J. Am. Chem. Soc. 117: 8737-8744.

Weber R, Hovda B, Schoendorff G, Wilson AK (2015).
Chem. Phys. Lett. 637: 120-126.

Weigend F, Ahlrichs R (2005) Phys Chem Chem Phys 7: 3297-3305.

Wolf R, Kaul BL (1992) Plastics, Additives. Ullmann's encyclopedia of industrial chemistry, Weinheim: $\mathrm{VCH}$.

Woon DE and Dunning Jr. TH (1993) J. Chem. Phys. 1358-1371.

Wren SW, Vogelhuber KM, Ichino T, Stanton JF, Lineberger WC (2012) J. Phys. Chem. A 116: 31183123.

Wright JS, Johnson ER, DiLabio GA (2001) J. Am. Chem. Soc. 123: 1173-1183.

Zhao Y, Truhlar DG (2008) Theor. Chem. Acc. 120: 215-241.

Zheng J, XU X, Truhlar DG (2011) Theor. Chem. Acc. 128: 295-305.

Zhu Q, Zhang XM, Fry AJ (1997) Polym. Degrad. Stab. 57: $43-50$

Tab. 1. Dihedral angles $\varphi$ (and $\varphi^{\prime}$ in aniline, where $\varphi=-\varphi^{\prime}$ ) in degrees for optimal geometries of electroneutral state of molecules and radicals. Values for radicals are in italics.

\begin{tabular}{|c|c|c|c|c|c|}
\hline Method & Basis set & $\mathbf{O}-\mathbf{H}$ & $\mathbf{S}-\mathbf{H}$ & $\mathrm{Se}-\mathrm{H}$ & $\mathbf{N}-\mathbf{H}$ \\
\hline \multirow{8}{*}{ B3LYP } & \multirow{2}{*}{$6-311++G(d, p)$} & 0 & 0 & 35 & \pm 24 \\
\hline & & - & - & - & 0 \\
\hline & \multirow{2}{*}{ aug-cc-pVTZ } & 0 & 0 & 0 & \pm 24 \\
\hline & & - & - & - & 0 \\
\hline & \multirow{2}{*}{ Sapporo } & 0 & 0 & 0 & \pm 24 \\
\hline & & - & - & - & 0 \\
\hline & \multirow{2}{*}{ ma-TZVP } & 0 & 0 & 0 & \pm 24 \\
\hline & & - & - & - & 0 \\
\hline \multirow{8}{*}{ M06-2X } & \multirow{2}{*}{$6-311++G(d, p)$} & 0 & 4 & 0 & \pm 25 \\
\hline & & - & - & - & 0 \\
\hline & \multirow{2}{*}{ aug-cc-pVTZ } & 0 & 1 & 0 & \pm 25 \\
\hline & & - & - & - & 0 \\
\hline & \multirow{2}{*}{ Sapporo } & 0 & 1 & 4 & \pm 25 \\
\hline & & - & - & - & 0 \\
\hline & \multirow{2}{*}{ ma-TZVP } & 0 & 0 & 0 & \pm 25 \\
\hline & & - & - & - & 0 \\
\hline \multirow{8}{*}{ PBE0 } & \multirow{2}{*}{$6-311++G(d, p)$} & 0 & 0 & 0 & \pm 25 \\
\hline & & - & - & - & 0 \\
\hline & \multirow{2}{*}{ aug-cc-pVTZ } & 0 & 0 & 0 & \pm 24 \\
\hline & & - & - & - & 0 \\
\hline & \multirow{2}{*}{ Sapporo } & 0 & 0 & 0 & \pm 27 \\
\hline & & - & - & - & 0 \\
\hline & \multirow{2}{*}{ ma-TZVP } & 0 & 0 & 0 & \pm 24 \\
\hline & & - & - & - & 0 \\
\hline \multirow{2}{*}{ PM7 } & & 0 & 0 & 0 & \pm 17 \\
\hline & & - & - & - & 0 \\
\hline \multirow{2}{*}{ G4 } & & 0 & 0 & 0 & \pm 26 \\
\hline & & - & - & - & 0 \\
\hline
\end{tabular}


Tab. 2. Dihedral angles $\varphi$ (and $\varphi^{\prime}$ in aniline, where $\left.\varphi=-\varphi^{\prime}\right) / \Theta, \Theta^{\prime}\left(\Theta=-\Theta^{\prime}\right.$ for all cases) in degrees for para-amino substituted neutral molecules and radicals. Values for radicals are in italics.

\begin{tabular}{|c|c|c|c|c|c|}
\hline Method & Basis set & $\mathbf{O}-\mathbf{H} / \mathrm{NH}_{2}$ & $\mathrm{~S}-\mathrm{H} / \mathrm{NH}_{2}$ & $\mathrm{Se}-\mathrm{H} / \mathrm{NH}_{2}$ & $\mathbf{N}-\mathbf{H} / \mathbf{N H}_{2}$ \\
\hline \multirow{8}{*}{ B3LYP } & \multirow{2}{*}{$6-311++G(d, p)$} & $0 / \pm 27$ & $92 / \pm 23$ & $91 / \pm 23$ & $\pm 27 / \pm 27$ \\
\hline & & $-/ \pm 13$ & $-/ \pm 15$ & $-/ \pm 17$ & $0 / \pm 19$ \\
\hline & \multirow{2}{*}{ aug-cc-pVTZ } & $0 / \pm 26$ & $91 / \pm 23$ & $91 / \pm 23$ & $\pm 27 / \pm 27$ \\
\hline & & $-/ \pm 12$ & $-/ \pm 15$ & $-/ \pm 16$ & $0 / \pm 19$ \\
\hline & \multirow{2}{*}{ Sapporo } & $0 / \pm 26$ & $91 / \pm 22$ & $91 / \pm 23$ & $\pm 27 / \pm 27$ \\
\hline & & $-/ \pm 11$ & $-/ \pm 14$ & $-/ \pm 16$ & $0 / \pm 18$ \\
\hline & \multirow{2}{*}{ ma-TZVP } & $1 / \pm 26$ & $91 / \pm 22$ & $91 / \pm 22$ & $\pm 27 / \pm 27$ \\
\hline & & $-/ \pm 12$ & $-/ \pm 14$ & $-/ \pm 15$ & $0 / \pm 18$ \\
\hline \multirow{8}{*}{ M06-2X } & \multirow{2}{*}{$6-311++\mathrm{G}(\mathrm{d}, \mathrm{p})$} & $1 / \pm 27$ & $89 / \pm 24$ & $91 / \pm 24$ & $\pm 28 / \pm 28$ \\
\hline & & $-/ \pm 11$ & $-/ \pm 15$ & $-/ \pm 26$ & $0 / \pm 19$ \\
\hline & \multirow{2}{*}{ aug-cc-pVTZ } & $0 / \pm 27$ & $89 / \pm 24$ & $89 / \pm 24$ & $\pm 28 / \pm 28$ \\
\hline & & $-/ \pm 11$ & $-/ \pm 15$ & $-/ \pm 25$ & $0 / \pm 18$ \\
\hline & \multirow{2}{*}{ Sapporo } & $0 / \pm 27$ & $89 / \pm 23$ & $94 / \pm 23$ & $\pm 27 / \pm 27$ \\
\hline & & $-/ \pm 9$ & $-/ \pm 13$ & $-/ \pm 25$ & $0 / \pm 18$ \\
\hline & \multirow{2}{*}{ ma-TZVP } & $0 / \pm 27$ & $93 / \pm 23$ & $89 / \pm 23$ & $\pm 27 / \pm 27$ \\
\hline & & $-/ \pm 9$ & $-/ \pm 13$ & $-/ \pm 25$ & $0 / \pm 17$ \\
\hline \multirow{8}{*}{ PBE0 } & \multirow{2}{*}{$6-311++G(d, p)$} & $0 / \pm 27$ & $92 / \pm 23$ & $91 / \pm 23$ & $\pm 27 / \pm 27$ \\
\hline & & $-/ \pm 13$ & $-/ \pm 15$ & $-/ \pm 25$ & $0 / \pm 20$ \\
\hline & \multirow{2}{*}{ aug-cc-pVTZ } & $0 / \pm 27$ & $91 / \pm 23$ & $91 / \pm 23$ & $\pm 27 / \pm 27$ \\
\hline & & $-/ \pm 13$ & $-/ \pm 15$ & $-/ \pm 17$ & $0 / \pm 19$ \\
\hline & \multirow{2}{*}{ Sapporo } & $0 / \pm 27$ & $91 / \pm 23$ & $91 / \pm 23$ & $\pm 27 / \pm 27$ \\
\hline & & $-/ \pm 12$ & $-/ \pm 14$ & $-/ \pm 25$ & $0 / \pm 19$ \\
\hline & \multirow{2}{*}{ ma-TZVP } & $1 / \pm 26$ & $92 / \pm 22$ & $91 / \pm 22$ & $\pm 27 / \pm 27$ \\
\hline & & $-/ \pm 12$ & $-/ \pm 14$ & $-/ \pm 24$ & $0 / \pm 19$ \\
\hline \multirow{2}{*}{ PM7 } & & $1 / 22$ & $91 / \pm 10$ & $91 / \pm 14$ & $\pm 23 / \pm 23$ \\
\hline & & $-/ 0$ & $-/ \pm 15$ & $-/ \pm 4$ & $0 / \pm 8$ \\
\hline \multirow{2}{*}{ G4 } & & $0 / \pm 28$ & $91 / \pm 25$ & $91 / \pm 25$ & $\pm 29 / \pm 29$ \\
\hline & & $-/ \pm 17$ & $-/ \pm 17$ & $-/ \pm 18$ & $0 / \pm 22$ \\
\hline
\end{tabular}


Tab. 3. Dihedral angles $\varphi$ (and $\varphi^{\prime}$ in aniline, where $\left.\varphi=-\varphi^{\prime}\right) / \Theta, \Theta^{\prime}\left(\Theta=-\Theta^{\prime}\right.$ for all cases), in degrees for para-nitro substituted neutral molecules and radicals. Values for radicals are in italics.

\begin{tabular}{|c|c|c|c|c|c|}
\hline Method & Basis set & $\mathbf{O}-\mathbf{H} / \mathrm{NO}_{2}$ & $\mathrm{~S}-\mathrm{H} / \mathrm{NO}_{2}$ & $\mathrm{Se}-\mathrm{H} / \mathrm{NO}_{2}$ & $\mathrm{~N}-\mathrm{H} / \mathrm{NO}_{2}$ \\
\hline \multirow{8}{*}{ B3LYP } & \multirow{2}{*}{$6-311++G(d, p)$} & $0 / 0$ & $0 / 0$ & $0 / 0$ & $\pm 18 / 0$ \\
\hline & & $-/ 0$ & $-/ 0$ & $-/ 0$ & $0 / 0$ \\
\hline & \multirow{2}{*}{ aug-cc-pVTZ } & $0 / 0$ & $0 / 0$ & $0 / 0$ & $\pm 18 / 0$ \\
\hline & & $-/ 0$ & $-/ 0$ & $-/ 0$ & $0 / 0$ \\
\hline & \multirow{2}{*}{ Sapporo } & $0 / 0$ & $0 / 0$ & $0 / 0$ & $\pm 17 / 0$ \\
\hline & & $-/ 0$ & $-/ 0$ & $-/ 0$ & $0 / 0$ \\
\hline & \multirow{2}{*}{ ma-TZVP } & $0 / 0$ & $0 / 0$ & $0 / 0$ & $\pm 17 / 0$ \\
\hline & & $-/ 0$ & $-/ 0$ & $-/ 0$ & $0 / 0$ \\
\hline \multirow{8}{*}{ M06-2X } & \multirow{2}{*}{$6-311++\mathrm{G}(\mathrm{d}, \mathrm{p})$} & $0 / 0$ & $2 / 0$ & $0 / 0$ & $\pm 20 / 0$ \\
\hline & & $-/ 0$ & $-/ 0$ & $-/ 0$ & $0 / 0$ \\
\hline & \multirow{2}{*}{ aug-cc-pVTZ } & $0 / 0$ & $0 / 0$ & $2 / 0$ & $\pm 19 / 0$ \\
\hline & & $-/ 0$ & $-/ 0$ & $-/ 0$ & $0 / 0$ \\
\hline & \multirow{2}{*}{ Sapporo } & $0 / 0$ & $0 / 0$ & $3 / 0$ & $\pm 19 / 0$ \\
\hline & & $-/ 0$ & $-/ 0$ & $-/ 0$ & $0 / 0$ \\
\hline & \multirow{2}{*}{ ma-TZVP } & $0 / 0$ & $0 / 0$ & $3 / 0$ & $\pm 19 / 0$ \\
\hline & & $-/ 0$ & $-/ 0$ & $-/ 0$ & $0 / 0$ \\
\hline \multirow{8}{*}{ PBE0 } & \multirow{2}{*}{$6-311++G(d, p)$} & $0 / 0$ & $0 / 0$ & $0 / 0$ & $\pm 18 / 0$ \\
\hline & & $-/ 0$ & $-/ 0$ & $-/ 0$ & $0 / 0$ \\
\hline & \multirow{2}{*}{ aug-cc-pVTZ } & $0 / 0$ & $0 / 0$ & $0 / 0$ & $\pm 18 / 0$ \\
\hline & & $-/ 0$ & $-/ 0$ & $-/ 0$ & $0 / 0$ \\
\hline & \multirow{2}{*}{ Sapporo } & $0 / 0$ & $0 / 0$ & $0 / 0$ & $\pm 17 / 0$ \\
\hline & & $-/ 0$ & $-/ 0$ & $-/ 0$ & $0 / 0$ \\
\hline & \multirow{2}{*}{ ma-TZVP } & $0 / 0$ & $0 / 0$ & $0 / 0$ & $\pm 19 / 0$ \\
\hline & & $-/ 0$ & $-/ 0$ & $-/ 0$ & $0 / 0$ \\
\hline \multirow{2}{*}{ PM7 } & & $0 / 0$ & $0 / 0$ & $0 / 0$ & $0 / 0$ \\
\hline & & $-/ 0$ & $-/ 0$ & $-/ 0$ & $0 / 0$ \\
\hline \multirow{2}{*}{ G4 } & & $0 / 0$ & $0 / 0$ & $0 / 0$ & $\pm 21 / 0$ \\
\hline & & $-/ 0$ & $-/ 0$ & $-/ 0$ & $0 / 0$ \\
\hline
\end{tabular}


Tab. 4. Dihedral angles $\varphi$ (and $\varphi^{\prime}$ in aniline, where $\left.\varphi=-\varphi^{\prime}\right) / \Theta, \Theta^{\prime}\left(\Theta=-\Theta^{\prime}\right.$ in degrees for radical cations and anions (in italics) formed from para-amino substituted molecules.

\begin{tabular}{|c|c|c|c|c|c|}
\hline Method & Basis set & $\mathbf{O}-\mathbf{H} / \mathbf{N H}_{2}$ & $\mathbf{S}-\mathbf{H} / \mathbf{N H}_{2}$ & $\mathrm{Se}-\mathrm{H} / \mathrm{NH}_{2}$ & $\mathbf{N}-\mathbf{H} / \mathbf{N H}_{2}$ \\
\hline \multirow{4}{*}{ B3LYP } & $6-311++G(d, p)$ & $\begin{array}{c}0 / 0 \\
-/ 59,121\end{array}$ & $\begin{array}{c}0 / 0 \\
-/ \pm 31\end{array}$ & $\begin{array}{c}0 / 0 \\
-/ \pm 31\end{array}$ & $\begin{array}{c}0 / 0 \\
0 /-60,-120\end{array}$ \\
\hline & aug-cc-pVTZ & $\begin{array}{c}0 / 0 \\
-/ 42,104\end{array}$ & $\begin{array}{c}0 / 0 \\
-/ \pm 31\end{array}$ & $\begin{array}{c}0 / 0 \\
-/ \pm 30\end{array}$ & $\begin{array}{c}0 / 0 \\
0 /-59,-121\end{array}$ \\
\hline & Sapporo & $\begin{array}{c}0 / 0 \\
-/ 81,143\end{array}$ & $\begin{array}{c}0 / 0 \\
-/ \pm 31\end{array}$ & $\begin{array}{c}0 / 0 \\
-/ \pm 30\end{array}$ & $\begin{array}{c}0 / 0 \\
0 /-59,-121\end{array}$ \\
\hline & ma-TZVP & $\begin{array}{c}0 / 0 \\
-/ 59,121\end{array}$ & $\begin{array}{c}0 / 0 \\
-/ \pm 31 \\
\end{array}$ & $\begin{array}{c}0 / 0 \\
-/ \pm 30 \\
\end{array}$ & $\begin{array}{c}0 / 0 \\
0 /-60,-120\end{array}$ \\
\hline \multirow{4}{*}{ M06-2X } & $6-311++\mathrm{G}(\mathrm{d}, \mathrm{p})$ & $\begin{array}{c}0 / 0 \\
-/ 59,121\end{array}$ & $\begin{array}{c}0 / 0 \\
-/ \pm 31\end{array}$ & $\begin{array}{l}91 / 0 \\
-/ \pm 31\end{array}$ & $\begin{array}{c}0 / 0 \\
0 /-59,-121\end{array}$ \\
\hline & aug-cc-pVTZ & $\begin{array}{c}0 / 0 \\
-/ 59,121\end{array}$ & $\begin{array}{c}0 / 0 \\
-/ \pm 31\end{array}$ & $\begin{array}{l}91 / 0 \\
-/ \pm 31\end{array}$ & $\begin{array}{c}0 / 0 \\
0 /-59,-121\end{array}$ \\
\hline & Sapporo & $\begin{array}{c}0 / 0 \\
-/ 59,121\end{array}$ & $\begin{array}{c}0 / 0 \\
-/ \pm 31\end{array}$ & $\begin{array}{c}91 / 0 \\
-/ \pm 30\end{array}$ & $\begin{array}{c}0 / 0 \\
0 /-59,-121\end{array}$ \\
\hline & ma-TZVP & $\begin{array}{c}0 / 0 \\
-/ 59,121 \\
\end{array}$ & $\begin{array}{c}0 / 0 \\
-/ \pm 31 \\
\end{array}$ & $\begin{array}{c}91 / 0 \\
-/ \pm 30 \\
\end{array}$ & $\begin{array}{c}0 / 0 \\
0 /-59,-121 \\
\end{array}$ \\
\hline \multirow{4}{*}{ PBE0 } & $6-311++G(d, p)$ & $\begin{array}{c}0 / 0 \\
-/ 59,121\end{array}$ & $\begin{array}{c}0 / 0 \\
-/ \pm 31\end{array}$ & $\begin{array}{c}0 / 0 \\
-/ \pm 31\end{array}$ & $\begin{array}{c}0 / 0 \\
0 /-59,-121\end{array}$ \\
\hline & aug-cc-pVTZ & $\begin{array}{c}0 / 0 \\
-/ 94,31\end{array}$ & $\begin{array}{c}0 / 0 \\
-/ \pm 31\end{array}$ & $\begin{array}{c}0 / 0 \\
-/ \pm 31\end{array}$ & $\begin{array}{c}0 / 0 \\
0 /-59,-121\end{array}$ \\
\hline & Sapporo & $\begin{array}{c}0 / 0 \\
-/ 88,150\end{array}$ & $\begin{array}{c}0 / 0 \\
-/ \pm 31\end{array}$ & $\begin{array}{c}0 / 0 \\
-/ \pm 30\end{array}$ & $\begin{array}{c}0 / 0 \\
0 /-59,-121\end{array}$ \\
\hline & ma-TZVP & $\begin{array}{c}0 / 0 \\
-/ 59,121\end{array}$ & $\begin{array}{c}0 / 0 \\
-/ \pm 31\end{array}$ & $\begin{array}{c}0 / 0 \\
-/ \pm 30\end{array}$ & $\begin{array}{c}0 / 0 \\
0 /-59,-121\end{array}$ \\
\hline PM7 & & $\begin{array}{c}0 / 0 \\
-/ \pm 31 \\
\end{array}$ & $\begin{array}{c}0 / 0 \\
-/ \pm 28\end{array}$ & $\begin{array}{c}0 / 0 \\
-/ \pm 26\end{array}$ & $\begin{array}{c}0 / 0 \\
0 /-59,-121\end{array}$ \\
\hline G4 & & $\begin{array}{c}0 / 0 \\
-/-92,25\end{array}$ & $\begin{array}{c}0 / 0 \\
-/ \pm 33\end{array}$ & $\begin{array}{l}0 / 0 \\
-/ 32\end{array}$ & $\begin{array}{c}0 / 0 \\
0 /-57,-123\end{array}$ \\
\hline
\end{tabular}


Tab. 5. Dihedral angles $\varphi$ (and $\varphi^{\prime}$ in aniline, where $\left.\varphi=-\varphi^{\prime}\right) / \Theta, \Theta^{\prime}\left(\Theta=-\Theta^{\prime}\right.$ for all cases) in degrees for radical cations and anions (in italics) formed from para-nitro substituted molecules.

\begin{tabular}{|c|c|c|c|c|c|}
\hline Method & Basis set & $\mathrm{O}-\mathrm{H} / \mathrm{NO}_{2}$ & $\mathbf{S}-\mathbf{H} / \mathrm{NO}_{2}$ & $\mathrm{Se}-\mathrm{H} / \mathrm{NO}_{2}$ & $\mathbf{N}-\mathbf{H} / \mathbf{N O}_{2}$ \\
\hline \multirow{8}{*}{ B3LYP } & \multirow{2}{*}{$6-311++\mathrm{G}(\mathrm{d}, \mathrm{p})$} & $0 / 46$ & $0 /-37$ & $-1 / 32$ & $0 /-33$ \\
\hline & & $-/ 0$ & $-/ 0$ & $-/ 0$ & $0 / 0$ \\
\hline & \multirow{2}{*}{ aug-cc-pVTZ } & $0 / 44$ & $1 /-34$ & $-1 / 28$ & $0 /-29$ \\
\hline & & $-/ 0$ & $-/ 0$ & $-/ 0$ & $0 / 0$ \\
\hline & \multirow{2}{*}{ Sapporo } & $0 / 45$ & $1 /-34$ & $0 / 39$ & $0 / 30$ \\
\hline & & $-/ 0$ & $-/ 0$ & $-/ 0$ & $0 / 0$ \\
\hline & \multirow{2}{*}{ ma-TZVP } & $0 / 45$ & $1 /-36$ & $-1 / 30$ & $0 / 31$ \\
\hline & & $-/ 0$ & $-/ 0$ & $-/ 0$ & $0 / 0$ \\
\hline \multirow{8}{*}{ M06-2X } & \multirow{2}{*}{$6-311++G(d, p)$} & $0 / 25$ & $0 /-12$ & $0 / 0$ & $0 / 11$ \\
\hline & & $-/ 0$ & $-/ 0$ & $-/ 0$ & $0 / 0$ \\
\hline & \multirow{2}{*}{ aug-cc-pVTZ } & $0 / 12$ & $0 / 0$ & $0 / 0$ & $0 / 0$ \\
\hline & & $-/ 0$ & $-/ 0$ & $-/ 0$ & $0 / 0$ \\
\hline & \multirow{2}{*}{ Sapporo } & $0 / 13$ & $0 / 0$ & $0 / 0$ & $0 / 0$ \\
\hline & & $-/ 0$ & $-/ 0$ & $-/ 0$ & $0 / 0$ \\
\hline & \multirow{2}{*}{ ma-TZVP } & $0 / 20$ & $0 / 0$ & $0 / 0$ & $0 / 0$ \\
\hline & & $-/ 0$ & $-/ 0$ & $-/ 0$ & $0 / 0$ \\
\hline \multirow{8}{*}{ PBE0 } & \multirow{2}{*}{$6-311++G(d, p)$} & $0 / 43$ & $0 /-32$ & $0 / 24$ & $0 /-27$ \\
\hline & & $-/ 0$ & $-/ 0$ & $-/ 0$ & $0 / 0$ \\
\hline & \multirow{2}{*}{ aug-cc-pVTZ } & $0 / 40$ & $1 /-27$ & $0 / 0$ & $0 / 22$ \\
\hline & & $-/ 0$ & $-/ 0$ & $-/ 0$ & $0 / 0$ \\
\hline & \multirow{2}{*}{ Sapporo } & $0 / 41$ & $1 /-27$ & $0 / 17$ & $0 / 22$ \\
\hline & & $-/ 0$ & $-/ 0$ & $-/ 0$ & $0 / 0$ \\
\hline & \multirow{2}{*}{ ma-TZVP } & $0 / 41$ & $0 /-29$ & $-1 / 21$ & $0 / 25$ \\
\hline & & $-/ 0$ & $-/ 0$ & $-/ 0$ & $0 / 0$ \\
\hline \multirow{2}{*}{ PM7 } & & $0 / 0$ & $0 / 0$ & $0 / 0$ & $0 / 0$ \\
\hline & & $-/ 0$ & $-/ 0$ & $-/ 0$ & $0 / 0$ \\
\hline \multirow{2}{*}{ G4 } & & $0 / 38$ & $-1 / 30$ & $-1 / 24$ & $0 / 0$ \\
\hline & & $-/ 0$ & $-/ 0$ & $-/ 0$ & $0 / 0$ \\
\hline
\end{tabular}


Tab. 6a. Bond dissociation enthalpies (in $\mathrm{kJ} \mathrm{mol}^{-1}$ ) of non-substituted molecules.

\begin{tabular}{|c|c|c|c|c|c|}
\hline Method & Basis set & $\begin{array}{c}\text { Phenol } \\
\text { O-H }\end{array}$ & $\begin{array}{c}\text { Thiophenol } \\
\text { S-H }\end{array}$ & $\begin{array}{c}\text { Benzeneselenol } \\
\mathrm{Se}-\mathrm{H} \\
\end{array}$ & $\begin{array}{c}\text { Aniline } \\
\mathbf{N}-\mathbf{H}\end{array}$ \\
\hline \multirow{4}{*}{ B3LYP } & $6-311++\mathrm{G}(\mathrm{d}, \mathrm{p})$ & 346.9 & 355.7 & 325.5 & 368.2 \\
\hline & aug-cc-pVTZ & 351.3 & 358.3 & 326.8 & 370.4 \\
\hline & Sapporo & 352.0 & 360.7 & 327.3 & 370.9 \\
\hline & ma-TZVP & 347.4 & 358.8 & 326.0 & 368.6 \\
\hline \multirow{4}{*}{ M06-2X } & 6-311++G(d,p) & 369.7 & 358.6 & 312.0 & 386.5 \\
\hline & aug-cc-pVTZ & 374.6 & 364.7 & 312.9 & 389.2 \\
\hline & Sapporo & 374.9 & 366.7 & 312.4 & 389.5 \\
\hline & ma-TZVP & 371.8 & 362.5 & 313.6 & 388.6 \\
\hline \multirow{4}{*}{ PBE0 } & 6-311++G(d,p) & 348.4 & 353.3 & 321.9 & 368.8 \\
\hline & aug-cc-pVTZ & 353.2 & 355.3 & 322.5 & 370.8 \\
\hline & Sapporo & 353.8 & 357.6 & 323.0 & 371.3 \\
\hline & ma-TZVP & 349.5 & 356.0 & 321.9 & 369.2 \\
\hline PM7 & & 312.7 & 329.6 & 308.5 & 328.6 \\
\hline G4 & & 367.4 & 335.3 & 306.7 & 381.6 \\
\hline Experiment & & $\begin{array}{c}368{\text { (isobutane })^{\mathrm{a}}} \\
372{\text { (benzene })^{\mathrm{a}}} \\
376^{\mathrm{b}}, 379^{\mathrm{c}} \\
367^{\mathrm{d}}, 369^{\mathrm{e}}\end{array}$ & $\begin{array}{l}332^{\mathrm{b}, 1} \\
331.0^{\mathrm{j}} \\
349.4^{\mathrm{k}}\end{array}$ & $\begin{array}{c}280.3^{\mathrm{f}} \\
326.4 \pm 16.7^{\mathrm{g}}\end{array}$ & $\begin{array}{l}386^{\mathrm{ch}} \\
373^{\mathrm{i}}\end{array}$ \\
\hline
\end{tabular}

Tab. 6b. Bond dissociation enthalpies (in $\mathrm{kJ} \mathrm{mol}^{-1}$ ) of para-amino derivatives.

\begin{tabular}{lccccc}
\hline Method & Basis set & O-H & S-H & Se-H & N-H \\
\hline \multirow{3}{*}{ B3LYP } & 6-311++G(d,p) & 310.4 & 295.7 & 281.6 & 343.4 \\
& aug-cc-pVTZ & 314.8 & 299.4 & 283.5 & 345.1 \\
& Sapporo & 315.2 & 301.7 & 284.0 & 345.5 \\
& ma-TZVP & 310.5 & 299.4 & 282.4 & 343.1 \\
M06-2X & 6-311++G(d,p) & 332.0 & 308.8 & 318.6 & 361.4 \\
& aug-cc-pVTZ & 336.6 & 313.2 & 317.4 & 363.3 \\
& Sapporo & 336.4 & 314.8 & 316.6 & 363.4 \\
PBE0 & ma-TZVP & 332.8 & 312.7 & 318.5 & 362.2 \\
\hline PM7 & 6-311++G(d,p) & 312.2 & 295.5 & 327.7 & 344.3 \\
\hline G4 & aug-cc-pVTZ & 317.1 & 299.2 & 321.9 & 345.9 \\
\hline Experiment & Sapporo & 317.4 & 301.5 & 327.0 & 346.2 \\
\hline
\end{tabular}


Tab. 6c. Bond dissociation enthalpies (in $\mathrm{kJ} \mathrm{mol}^{-1}$ ) of para-nitro derivatives.

\begin{tabular}{lccccc}
\hline Method & Basis set & O-H & S-H & Se-H & N-H \\
\hline \multirow{3}{*}{ B3LYP } & 6-311++G(d,p) & 364.5 & 355.8 & 325.7 & 385.8 \\
& aug-cc-pVTZ & 368.5 & 358.5 & 326.9 & 387.4 \\
& Sapporo & 369.1 & 360.8 & 327.4 & 388.0 \\
& ma-TZVP & 364.8 & 359.1 & 326.2 & 386.1 \\
\hline \multirow{3}{*}{ M06-2X } & 6-311++G(d,p) & 387.4 & 359.4 & 312.8 & 403.3 \\
& aug-cc-pVTZ & 392.0 & 362.8 & 313.4 & 405.3 \\
& Sapporo & 392.2 & 364.7 & 312.8 & 405.7 \\
PBE0 & ma-TZVP & 389.2 & 363.3 & 314.0 & 404.8 \\
\hline PM7 & 6-311++G(d,p) & 366.2 & 353.7 & 322.2 & 386.7 \\
\hline G4 & aug-cc-pVTZ & 370.4 & 355.5 & 322.7 & 387.8 \\
\hline Experiment & Sapporo & 371.0 & 357.8 & 323.1 & 388.4 \\
\hline
\end{tabular}

${ }^{\mathrm{a}}$ Wayner et al., 1995; ${ }^{\mathrm{b}}$ Bordwell and Cheng, 1991; 'Zhu et al., 1997; ${ }^{\mathrm{d} D e n i s o v, ~ 1995 ; ~}{ }^{\mathrm{e}}$ Lind et al., 1990; ${ }^{\mathrm{f}}$ Newcomb et al., 1991; ${ }^{\mathrm{g}}$ Leeck et al., 1996; ${ }^{\mathrm{h}}$ Bordwell et al., 1993; 'Jonsson et al., 1994; ${ }^{j}$ Bordwell et al., 1994; ${ }^{\mathrm{k}}$ Dos Santos et al., 2002; ${ }^{1}$ Venimadhavan et al., 1992; ${ }^{\mathrm{m}}$ Luo, 2007.

Tab. 7a. Ionization potentials (in $\mathrm{kJ} \mathrm{mol}^{-1}$ ) of non-substituted molecules.

\begin{tabular}{lccccc}
\hline Method & Basis set & Phenol & Thiophenol & Benzeneselenol & Aniline \\
\hline \multirow{3}{*}{ B3LYP } & 6-311++G(d,p) & 807.1 & 786.2 & 775.1 & 731.3 \\
& aug-cc-pVTZ & 804.2 & 784.4 & 774.0 & 730.2 \\
& Sapporo & 804.9 & 783.7 & 774.5 & 730.5 \\
& ma-TZVP & 804.0 & 783.0 & 774.0 & 729.5 \\
\hline \multirow{2}{*}{ M06-2X } & 6-311++G(d,p) & 824.4 & 806.7 & 798.9 & 748.7 \\
& aug-cc-pVTZ & 822.1 & 807.9 & 795.8 & 748.6 \\
& Sapporo & 822.1 & 806.7 & 794.4 & 748.1 \\
PBE0 & ma-TZVP & 820.5 & 803.0 & 794.9 & 746.4 \\
\hline PM7 & 6-311++G(d,p) & 805.4 & 786.8 & 774.8 & 729.1 \\
\hline G4 & aug-cc-pVTZ & 802.1 & 784.4 & 773.5 & 727.8 \\
\hline Experiment & Sapporo & 802.8 & 783.7 & 774.0 & 728.1 \\
\hline
\end{tabular}


Tab. 7b. Ionization potentials (in $\mathrm{kJ} \mathrm{mol}^{-1}$ ) of para-amino derivatives.

\begin{tabular}{lccccc}
\hline Method & Basis set & Phenol & Thiophenol & Benzeneselenol & Aniline \\
\hline \multirow{3}{*}{ B3LYP } & 6-311++G(d,p) & 685.6 & 687.6 & 685.7 & 632.3 \\
& aug-cc-pVTZ & 682.8 & 684.1 & 683.0 & 630.4 \\
& Sapporo & 683.1 & 683.6 & 683.1 & 630.7 \\
& ma-TZVP & 681.8 & 682.7 & 682.5 & 629.1 \\
\hline \multirow{2}{*}{ M06-2X } & 6-311++G(d,p) & 702.7 & 708.5 & 831.6 & 649.4 \\
& aug-cc-pVTZ & 700.8 & 704.9 & 825.8 & 648.3 \\
& Sapporo & 700.5 & 703.7 & 824.0 & 648.0 \\
PBE0 & ma-TZVP & 698.3 & 702.5 & 826.2 & 645.6 \\
\hline PM7 & 6-311++G(d,p) & 682.7 & 686.7 & 685.1 & 629.6 \\
\hline G4 & aug-cc-pVTZ & 679.3 & 682.7 & 681.9 & 627.4 \\
\hline
\end{tabular}

Tab. 7c. Ionization potentials (in $\mathrm{kJ} \mathrm{mol}^{-1}$ ) of para-nitro derivatives.

\begin{tabular}{lccccc}
\hline Method & Basis set & Phenol & Thiophenol & Benzeneselenol & Aniline \\
\hline \multirow{3}{*}{ B3LYP } & 6-311++G(d,p) & 879.6 & 853.2 & 839.1 & 807.9 \\
& aug-cc-pVTZ & 873.8 & 848.5 & 835.3 & 803.6 \\
& Sapporo & 874.3 & 847.7 & 835.8 & 804.1 \\
& ma-TZVP & 873.7 & 847.5 & 835.5 & 803.6 \\
\hline \multirow{2}{*}{ M06-2X } & 6-311++G(d,p) & 906.8 & 877.8 & 863.0 & 828.2 \\
& aug-cc-pVTZ & 901.1 & 873.1 & 857.0 & 824.6 \\
& Sapporo & 900.9 & 871.8 & 855.4 & 824.4 \\
PBE0 & ma-TZVP & 899.8 & 871.2 & 856.7 & 823.3 \\
\hline PM7 & 6-311++G(d,p) & 879.2 & 854.1 & 838.5 & 805.8 \\
G4 & aug-cc-pVTZ & 872.9 & 848.4 & 834.2 & 800.8 \\
\hline Experiment & Sapporo & 873.4 & 847.8 & 834.7 & 801.2 \\
\hline
\end{tabular}

a'Lipert and Colson, 1990; ' Faulk et al., 1990; 'Takahashi et al., 1992; 'Kobayashi and Nagakura, 1975; 'Potapov et al., 1972. 
Tab. 8a. Proton affinities (in $\mathrm{kJ} \mathrm{mol}^{-1}$ ) of non-substituted molecules.

\begin{tabular}{|c|c|c|c|c|c|}
\hline Method & Basis set & $\begin{array}{c}\text { Phenol } \\
\text { O-H }\end{array}$ & $\begin{array}{c}\text { Thiophenol } \\
\text { S-H }\end{array}$ & $\begin{array}{c}\text { Benzeneselenol } \\
\mathrm{Se}-\mathrm{H} \\
\end{array}$ & $\begin{array}{c}\text { Aniline } \\
\mathbf{N}-\mathbf{H}\end{array}$ \\
\hline \multirow{4}{*}{ B3LYP } & $6-311++G(d, p)$ & 1450.1 & 1412.1 & 1392.9 & 1533.6 \\
\hline & aug-cc-pVTZ & 1456.9 & 1419.5 & 1397.7 & 1537.0 \\
\hline & Sapporo & 1457.4 & 1422.5 & 1398.6 & 1537.4 \\
\hline & ma-TZVP & 1452.7 & 1419.7 & 1396.1 & 1535.5 \\
\hline \multirow{4}{*}{ M06-2X } & 6-311++G(d,p) & 1452.9 & 1403.1 & 1377.2 & 1530.7 \\
\hline & aug-cc-pVTZ & 1457.1 & 1413.6 & 1384.1 & 1531.9 \\
\hline & Sapporo & 1457.6 & 1415.9 & 1386.3 & 1532.5 \\
\hline & ma-TZVP & 1455.8 & 1411.6 & 1382.3 & 1533.1 \\
\hline \multirow{4}{*}{ PBE0 } & 6-311++G(d,p) & 1454.5 & 1413.2 & 1393.6 & 1538.2 \\
\hline & aug-cc-pVTZ & 1461.7 & 1420.4 & 1398.2 & 1541.4 \\
\hline & Sapporo & 1462.2 & 1423.5 & 1399.1 & 1541.8 \\
\hline & ma-TZVP & 1457.7 & 1420.8 & 1396.7 & 1540.0 \\
\hline PM7 & & 1390.4 & 1366.3 & 1347.5 & 1461.3 \\
\hline G4 & & 1461.3 & 1421.0 & 1394.0 & 1537.8 \\
\hline \multirow{3}{*}{ Experiment } & & $1461^{\mathrm{a}}$ & \multirow{3}{*}{$1424^{\mathrm{d}}$} & & \multirow{3}{*}{$\begin{array}{l}1541^{\mathrm{e}} \\
1533^{\mathrm{c}}\end{array}$} \\
\hline & & $1450^{\mathrm{b}}$ & & & \\
\hline & & $1462^{\mathrm{c}}$ & & & \\
\hline
\end{tabular}

Tab. 8b. Proton affinities (in $\mathrm{kJ} \mathrm{mol}^{-1}$ ) of para-amino derivatives.

\begin{tabular}{lccccc}
\hline Method & Basis set & O-H & S-H & Se-H & N-H \\
\hline \multirow{3}{*}{ B3LYP } & 6-311++G(d,p) & 1466.9 & 1432.2 & 1412.9 & 1549.6 \\
& aug-cc-pVTZ & 1475.1 & 1437.9 & 1416.5 & 1553.7 \\
& Sapporo & 1457.4 & 1422.5 & 1398.6 & 1537.4 \\
& ma-TZVP & 1452.7 & 1419.7 & 1396.1 & 1535.5 \\
\hline \multirow{2}{*}{ M06-2X } & 6-311++G(d,p) & 1467.8 & 1421.9 & 1396.8 & 1545.4 \\
& aug-cc-pVTZ & 1474.1 & 1428.2 & 1401.8 & 1548.2 \\
& Sapporo & 1474.9 & 1430.8 & 1403.9 & 1549.0 \\
PBE0 & ma-TZVP & 1472.6 & 1429.7 & 1400.8 & 1549.0 \\
\hline PM7 & 6-311++G(d,p) & 1472.2 & 1433.5 & 1414.6 & 1555.3 \\
\hline G4 & aug-cc-pVTZ & 1481.0 & 1439.5 & 1417.7 & 1559.5 \\
\hline Experiment & Sapporo & 1481.7 & 1442.9 & 1418.7 & 1560.1 \\
\hline
\end{tabular}


Tab. 8c. Proton affinities (in $\mathrm{kJ} \mathrm{mol}^{-1}$ ) of para-nitro derivatives.

\begin{tabular}{lccccc}
\hline Method & Basis set & O-H & S-H & Se-H & N-H \\
\hline \multirow{3}{*}{ B3LYP } & 6-311++G(d,p) & 1347.2 & 1328.1 & 1314.9 & 1424.0 \\
& aug-cc-pVTZ & 1356.1 & 1337.6 & 1321.9 & 1429.6 \\
& Sapporo & 1356.6 & 1340.4 & 1322.9 & 1430.1 \\
& ma-TZVP & 1351.8 & 1337.6 & 1320.3 & 1428.1 \\
\hline \multirow{2}{*}{ M06-2X } & 6-311++G(d,p) & 1354.3 & 1326.6 & 1307.9 & 1425.8 \\
& aug-cc-pVTZ & 1360.4 & 1336.1 & 1316.3 & 1428.9 \\
& Sapporo & 1361.3 & 1338.5 & 1314.7 & 1430.1 \\
PBE0 & ma-TZVP & 1359.2 & 1336.9 & 1318.6 & 1431.9 \\
& 6-311++G(d,p) & 1354.6 & 1331.9 & 1325.5 & 1437.5 \\
\hline PM7 & aug-cc-pVTZ & 1364.0 & 1341.7 & 1326.5 & 1438.0 \\
\hline G4 & Sapporo & 1364.5 & 1344.5 & 1323.9 & 1436.0 \\
\hline \multirow{2}{*}{ Experiment } & ma-TZVP & 1359.7 & 1341.7 & 1290.7 & 1355.7 \\
\hline
\end{tabular}

${ }^{\mathrm{a}}$ Fujio et al., 1981; ${ }^{\mathrm{b}} \mathrm{McMahon}$ and Kebarle, 1977; ${ }^{\mathrm{C} B a r t m e s s}$ et al., 1979; ${ }^{\mathrm{d}}$ Taft and Bordwell, 1988; ${ }^{\mathrm{e}}$ Wren et al., 2012.
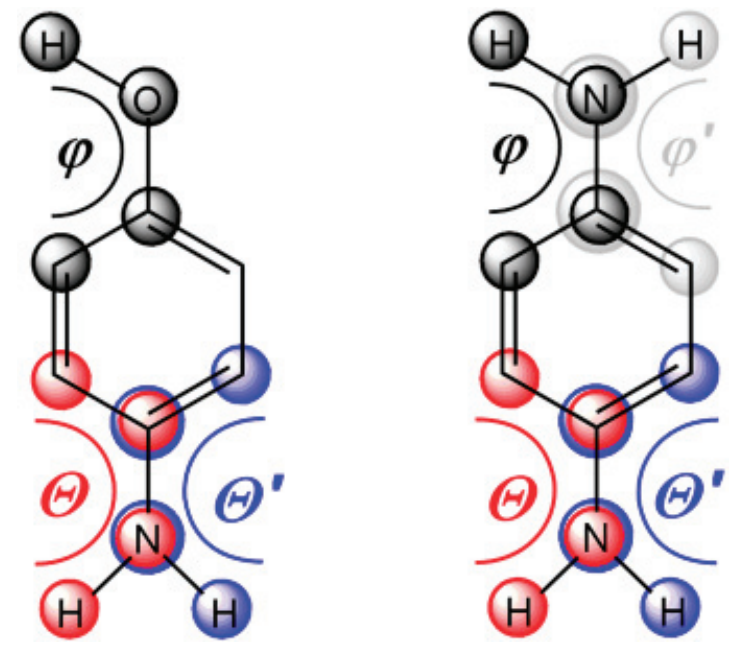

Fig. 1. Notation of dihedral angles $\Theta / \Theta^{\prime}$ and $\varphi / \varphi^{\prime}$ in para-aminophenol and para-aminoaniline molecules. Notation is valid for all studied molecules. 


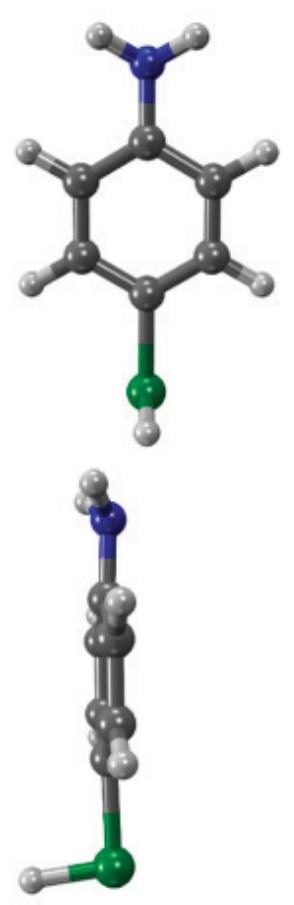

a)

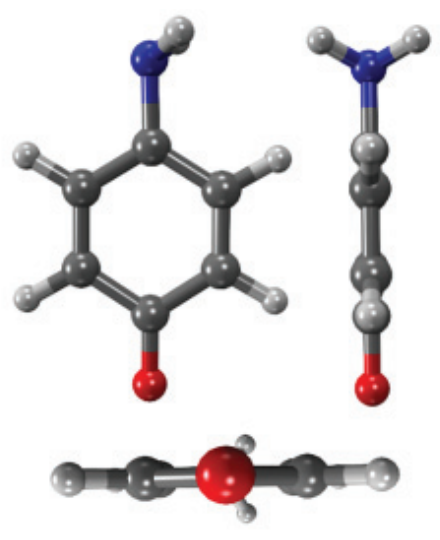

b)

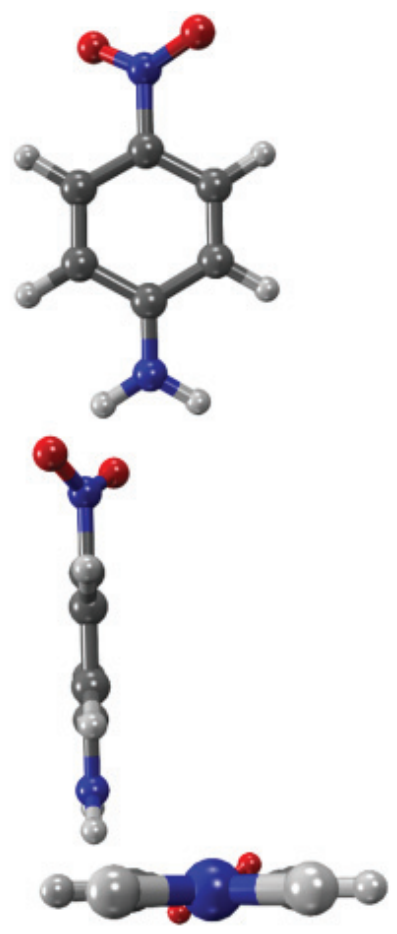

c)

Fig. 2. Selected optimal B3LYP/6-311++G(d,p) geometries of para-aminobenzeneselenol with mirror plane of amino group perpendicular to the benzene ring plane (hydrogens of amino group are tilted from the ring plane) and twisted - $\mathrm{SeH}$ group (a), deprotonated para-aminophenol with mirror plane of amino group corresponding to the ring plane (b) and para-nitroaniline with rotated nitro group (c). 